\title{
LETTER
}

\section{Kallistatin - the score beats the marker}

\author{
Steven Draikiwicz', Kristina Katz*, Ashish Tikotekar² and Amay Parikh² \\ See related research by Lin et al., http://ccforum.com/content/17/1/R27
}

We appreciate the efforts of Lin and colleagues' study using kallistatin to detect the severity of communityacquired pneumonia (CAP); however, we do have some concerns [1].

Of the gold standards to which kallistatin was compared, only the CURB-65 score was statistically significant to predict mortality. We should anticipate that the previously validated Sequential Organ Failure Assessment (SOFA) and Acute Physiology and Chronic Health Evaluation (APACHE) II scores would also be statistically significant; however, in the study they are not. The expensive and time-consuming blood test is questioned when bedside, inexpensive and quick scoring systems have non-inferior results in predicting outcomes.

There were many patients in the high mortality group with sepsis and acute respiratory distress syndrome (ARDS), and in whom kallistatin has been shown to be consumed $[2,3]$. These factors are confounders, invalidating the observation that kallistatin levels were altered by severe CAP alone.

The authors note that kallistatin is produced mostly by the liver. The paper notes patients with cirrhosis, but does not provide details of other liver diseases, liver function test values, or patients with ischemic hepatopathy. In these diseases alone kallistatin would be decreased.

Finally, the study was based upon prior in vitro data that showed that kallistatin inhibits kallikrein activity [4]. In the study, however, kallikrein was not altered in either group. This questions the overall impact of kallistatin inhibition of kallikrein in vivo.
We thank the authors for attempting to validate kallistatin as a marker of severe CAP. This study shows that simple, inexpensive and time-saving scoring methods are equally effective, limiting the widespread use of kallistatin.

\section{Abbreviations}

CAP, community-acquired pneumonia.

\section{Competing interests}

The authors declare that they have no competing interests.

\section{Author details}

'Division of General Internal Medicine, Department of Medicine, Robert Wood Johnson Medical School, 1 Robert Wood Johnson Place, PO Box 19, New Brunswick, NJ 08903-0019, USA. ²Division of Pulmonary and Critical Care Department of Medicine, Robert Wood Johnson Medical School, 1 Robert Wood Johnson Place, PO Box 19, New Brunswick, NJ 08903-0019, USA.

Published: 23 April 2013

\section{References}

1. Lin WC, Lu SL, Lin CF, Chen CW, Chao L, Chao J, Lin YS: Plasma kallistatin levels in patients with severe community-acquired pneumonia. Crit Care 2013, 17:R27.

2. Liu Y, Bledsoe G, Hagiwara M, Shen B, Chao L, Chao J: Depletion of endogenous kallistatin exacerbates renal and cardiovascular oxidative stress, inflammation, and organ remodeling. Am J Physiol Renal Physiol 2012, 303:F1230-1238.

3. Chao J, Schmaier A, Chen LM, Yang Z, Chao L: Kallistatin, a novel human tissue kallikrein inhibitor: levels in body fluids, blood cells, and tissues in health and disease. J Lab Clin Med 1996, 127:612-620.

4. Zhou GX, Chao L, Chao J: Kallistatin: a novel human tissue kallikrein inhibitor. Purification, characterization, and reactive center sequence. J Biol Chem 1992, 267:25873-25880.

doi: $10.1186 /$ cc12576

Cite this article as: Draikiwicz S, et al.: Kallistatin - the score beats the marker. Critical Care 2013, 17:429.

*Correspondence: katzkn@gmail.com

'Division of General Internal Medicine, Department of Medicine, Robert

Wood Johnson Medical School, 1 Robert Wood Johnson Place, PO Box 19

New Brunswick, NJ 08903-0019, USA

Full list of author information is available at the end of the article 